\title{
Minimising Energy Losses: \\ Optimal Accommodation and Smart Operation of Renewable Distributed Generation
}

\author{
Luis F. Ochoa, Member, IEEE, and Gareth P. Harrison, Member, IEEE
}

\begin{abstract}
The problem of minimising losses in distribution networks has traditionally been investigated using a single, deterministic demand level. This has proved to be effective since most approaches are generally able to also result in minimum overall energy losses. However, the increasing penetration of (firm and variable) Distributed Generation (DG) raises concerns on the actual benefits of loss minimisation studies that are limited to a single demand/generation scenario. Here, a multi-period AC Optimal Power Flow (OPF) is used to determine the optimal accommodation of (renewable) DG in a way that minimises the system energy losses. In addition, control schemes expected to be part of the future Smart Grid, such as coordinated voltage control and dispatchable DG power factor, are embedded in the OPF formulation to explore the extra loss reduction benefits that can be harnessed with such technologies. The trade-off between energy losses and more generation capacity is also investigated. The methodology is applied to a generic UK distribution network and results demonstrate the significant impact that considering time-varying characteristics has on the energy loss minimisation problem and highlight the gains that the flexibility provided by innovative control strategies can have on both loss minimisation and generation capacity.
\end{abstract}

Index Terms-Distributed generation, energy losses, wind power, optimal power flow, smart grids, distribution networks.

\section{INTRODUCTION}

$\mathrm{E}$ NERGY LOSSES have been and will remain as one of the metrics used to assess distribution network performance. In liberalised electricity markets (e.g., UK) regulators provide economic incentives to those distribution network operators (DNOs) that outperform targets set for a given period (e.g., allowed loss percentages). Even where targets vary according to the specific geographical or legacy circumstances of each DNO, underachievers are subject to economic penalties. Incentive-based regulation, towards higher performance networks, is the main driver for minimising losses in distribution systems.

Traditionally, loss minimisation has focussed on optimising

This work is part-funded through the EPSRC Supergen V, UK Energy Infrastructure (AMPerES) grant in collaboration with UK electricity network operators working under Ofgem's Innovation Funding Incentive scheme - full details on http://www.supergen-amperes.org/.

The authors are with the Institute for Energy Systems, School of Engineering, University of Edinburgh, Edinburgh, EH9 3JL, U.K. (e-mail: luis_ochoa@ieee.org, gareth.harrison@ed.ac.uk) network (re)configuration [1, 2] or reactive power support through capacitor placement [3, 4]. However, the transition from passive distribution networks to active, low-carbon ones presents opportunities. Although planning issues, the regulatory framework, and the availability of resources limit DNOs and developers in their ability to accommodate (renewable) Distributed Generation (DG), governments are incentivising low-carbon technologies, as a means of meeting environmental targets and increasing energy security. This momentum can be harnessed by DNOs to bring network operational benefits through lower losses delivered by investment in DG. The unbundling rules in liberalised markets preclude ownership of DG by DNOs and prevent the DNO from directly planning the location and size of DG units. However, through the provision of information and incentives DNOs can indirectly steer third party investment in DG towards technically and economically beneficial locations.

The optimal accommodation and operation of DG plants to minimise losses has attracted the interest of the research community in the last fifteen years. The studies found in the literature can be classified into two approaches: minimisation of power losses, and minimisation of energy losses.

Minimisation of Power Losses. Although extensively used when considering passive networks (without DG), this approach only caters for a single load level making it impossible to determine the actual impact of variable forms of DG (wind, photovoltaics, etc.). This is particularly true with significant reverse power flows (and losses) occurring during rated output and minimum load conditions. The inherent variability of loads means the reduction of losses brought about by the 'optimal' size and location of a firm (e.g., gas) DG unit during maximum demand might not occur at other loading levels, resulting in non-optimal energy losses for a given horizon. This approach has been tackled using impact indices [5, 6], metaheuristics [7, 8], analytical methods [9-12], classical methods [13-15] and other techniques [16-18].

Minimisation of Energy Losses. Capturing the effects that the variability of both demand and (renewable) generation has on total energy losses for a given horizon is essential as it considers the actual metrics used by DNOs [19]. Modeling DG plants as firm generation (to some extent a less complex optimisation problem) was adopted for loss analyses using Tabu Search [20] or Genetic Algorithm (GA)-based multiobjective approaches [21]. As for variable (renewable) 
generation, the optimal allocation of DG plants based on impact indices (including losses) was previously proposed by the authors in [22], and extended to a GA-based multiobjective formulation in [23]. Energy losses were also considered in reference [24], where it was presented a multiresource GA-based multiobjective technique that catered for some aspects of active network management through the use of a linearised Optimal Power Flow (OPF). Energy loss minimisation was also studied in [25] through the optimal mix of statistically-modelled renewable sources considering a passive approach to network management.

Overall, few studies properly investigate the energy loss minimisation problem (as single or multiple objectives) considering time-varying demand and generation. Additionally, the potential advantages of adopting real-time control and communication systems as part of the future Smart Grid [26] for loss reduction have been largely neglected. Here, a multi-period AC Optimal Power Flow technique is adopted to minimise energy losses by optimally accommodating variable DG and employing innovative control schemes. It employs the same computational framework originally developed to determine the volume of DG that can be accommodated within distribution networks [26-28]. However, it has a distinct and separate contribution through its application to loss minimisation particularly with regard to the potential benefits of Smart Grid technologies. The method effectively captures the time-variation of multiple renewable sites and demand as well as the effect of innovative control schemes within the OPF.

This paper is structured as follows: first, a simple test feeder is used to contrast the power and energy loss minimisation approaches. Section III presents the lossminimising multi-period OPF and its embedded Smart Gridbased schemes. In Section IV, the method is applied to a generic UK distribution network using real demand and wind speed data: the findings demonstrate the significant impact of time-variation on energy losses and highlights the benefits of Smart Grid strategies for both loss minimisation and renewable penetrations. Finally, section V concludes the work.

\section{Power Losses Vs ENERgy Losses}

The 'optimal' accommodation and sizing of DG units where the time-varying characteristics of demand are neglected is very likely to lead to sub-optimal results. Fig. 1 presents a simple 4-bus test feeder with a total peak demand of 7.5MW (network parameters are given in Table II, Appendix). A $1.01 \mathrm{pu}$ target voltage at the grid supply point (GSP) secondary busbar is assumed. In order to investigate the impact of DG on losses three cases are evaluated:

1. Maximum Demand - a 'power only' snapshot at fixed maximum DG output and fixed maximum demand;

2. Variable Demand - an energy analysis at fixed maximum DG output and an annual load curve presented in Table I (Appendix), and;

3. Variable Demand and DG - an energy analysis where DG output is driven by wind power data and demand varies as in case 2 .
Operating the DG unit at unity power factor, Fig. 2 shows the resulting percentage losses relative to the power and energy delivered (to consumers). In all cases a distinct $u$-shape $[5,19]$ is evident as DG capacity initially lowers losses before higher capacities see losses rise. The loss benefits vary between the approaches and the maximum demand 'power only' analysis may be over- or under-estimating losses depending on the size of the DG. The maximum demand analysis results in a larger capacity at which minimum losses occur (see the arrows in Fig. 2) but the losses are lower than the more realistic 'energy' analyses. When the variability of wind power is introduced the reduction in energy losses is less significant as most of the time the actual power injection is lower than the nominal capacity.

The impact of DG units on energy losses will depend on the specific characteristics of the network, such as demand distribution and behaviour, topology, as well as the relative location of the generators and whether their output is firm or variable. Incorporating these complexities into an optimisation framework for energy loss minimisation is a challenge that has only been (partially) addressed by a few studies.

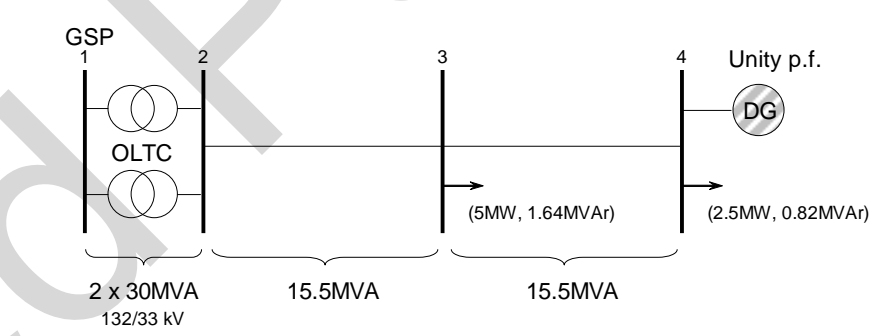

Fig. 1. One-line diagram for the 4-bus test feeder at maximum load.

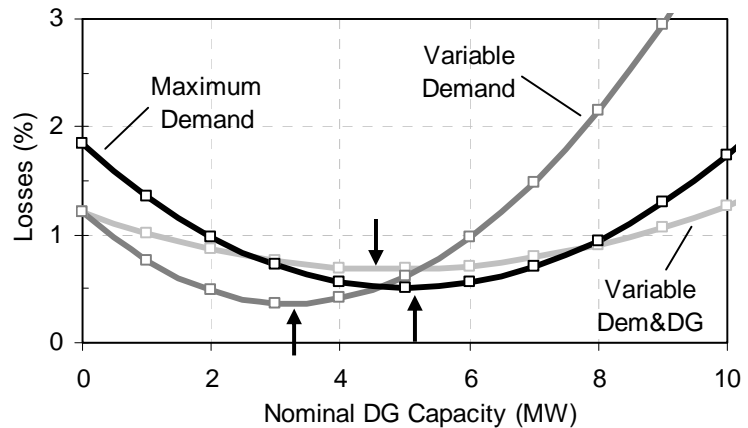

Fig. 2. Percentage power losses (peak demand) and annual energy losses relative to the delivered power and energy, respectively.

\section{FORMULATING THE ENERGy LOSS MinimisATION} Problem using a Multi-Period AC Optimal PoWer Flow

Optimal Power Flow [29] is widely accepted and mainly used to solve the economic dispatch problem. It can be adapted for different objectives and constraints with, e.g., an OPF-like (reduced gradient) method applied to a (power) loss minimisation problem [13]. A similar formulation with the objective of maximising DG capacity has also been adopted in [30-33]. However, in these OPF-based approaches, only peak demand and passive operation of the network were considered.

Here, the OPF framework previously developed in [26-28] is tailored to minimise energy losses across a given time horizon. The process is designed for balanced distribution systems such as those in operation in the UK and could be 
combined with capacitor placement using a method similar to [34]. Thermal and voltage constraints are accounted for while catering for the variability of both demand and generation and the use of Smart Grid-based control schemes. The framework for handling the variability of, and inter-relationships between, demand and generation as well as the salient points of the mathematical formulation are briefly outlined.

\section{A. Framework for Handling Variable Resources and Demand}

In networks with significant volumes of variable DG robust assessment of power flows are often best based on hourly historic demand and resource time series covering at least a year [35, 36]. For optimisation applications and depending on the size of the network, number of DG units, control schemes, etc., analysis of a whole year's time series imposes a significant computational burden. To diminish the number of periods to be evaluated whilst preserving the behaviour and inter-relationships between resource and demand, Ochoa et al. [26] used a process of discretisation and then aggregation according to the characteristics of 'similar' periods. To illustrate this, Fig. 3 (top) presents a week-long snapshot of hourly demand and wind power data for central Scotland in 2003 [37]. Fig. 3 (bottom) shows the discrete values following the allocation of the original data into a series of 7 bins covering specific ranges $(\{0\},(0,0.2 \mathrm{pu}],(0.2 \mathrm{pu}, 0.4 \mathrm{pu}], \ldots$, $(0.8 \mathrm{pu}, 1.0 \mathrm{pu}),\{1.0\})$ in which the mean values (e.g., $0.3 \mathrm{pu}$ for the $(0.2 \mathrm{pu}, 0.4 \mathrm{pu}]$ range) characterise each new hour. The aggregation process groups hours in which the same combination of demand and generation occur. For instance, the arrows point to hours where demand is $0.7 \mathrm{pu}$ and wind is zero; these conditions occur for a total of 18 hours in this particular week. This will constitute a period to be evaluated along with other combinations each with different overall duration in the optimisation problem. Ochoa et al. [26] provides a more detailed treatment of the framework.
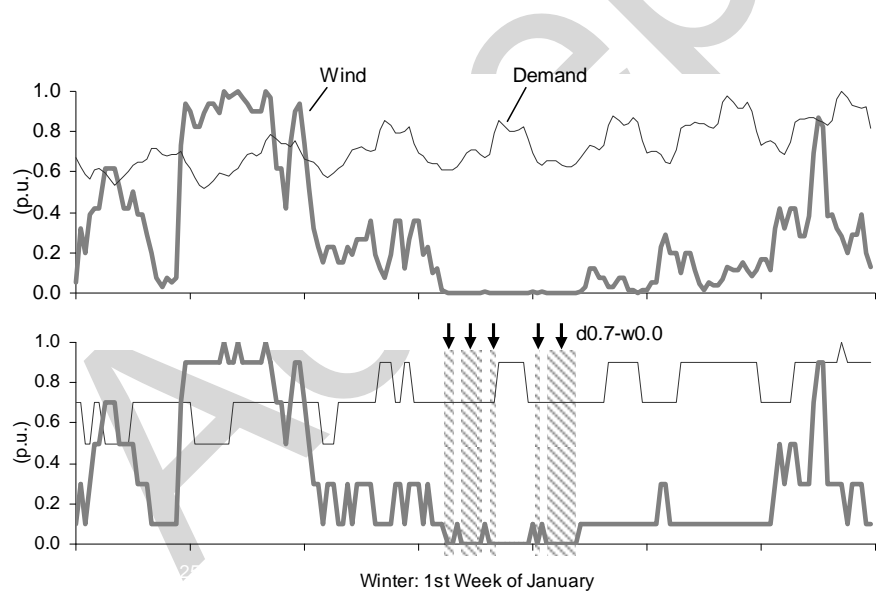

Fig. 3. (Top) Winter week hourly demand and wind power for central Scotland, 2003 [37]. (Bottom) Discretised data processed before aggregating the coincident hours of each demand-generation scenario.

\section{B. Multi-Period AC Optimal Power Flow}

The objective function of this loss analysis-focussed AC OPF is the minimisation of the total energy (line) losses over a given time horizon. The multi-periodicity, in terms of demand/generation combinations is achieved by providing each combination, $m$, with a different set of power flow variables with a unique, inter-period set of generation capacity variables is used throughout the analysis [26].

The basic multi-period AC OPF formulation minimises the total energy losses of the network over a time horizon comprising $m$ periods, $m \in M$. Using the elements of the $\mathrm{OPF}$, the objective function is formulated as:

$$
\min \sum_{m \in M}\left(\sum_{l \in L} f_{l, m}^{1, P}+f_{l, m}^{2, P}\right) \cdot \tau_{m}
$$

where $f_{l, m}^{1, P}$ and $f_{l, m}^{2, P}$ are the active power injections at each end (denoted 1 and 2) of branch $l, l \in L$; and, $\tau_{m}$ is the duration of period $\mathrm{m}$. The difference between the net injections at each end of the branch defines the energy loss. The objective is subject to a range of constraints including bus voltage and branch thermal limits but security, voltage step and fault level constraints, which can be implemented within the same framework [31-33], are not considered here to ensure clarity. No capacity constraint is placed on the new DG units since the aim is to accommodate as much capacity as is required to minimise the energy losses. A full mathematical specification is given in [26].

\section{Incorporating Smart Control Schemes}

Traditional (passive) networks specify fixed values for substation secondary voltages and operate DG units at constant power factors over all load conditions. While DNOs may vary the substation voltage seasonally or specify power factors on a time-of-day basis, neither is actively dispatched. To facilitate understanding of the potential influence of Smart Grid-based control schemes on loss reduction, a series of variables and constraints are incorporated in the method. Here, coordinated voltage control (CVC) and adaptive power factor control $(\mathrm{PFc})$ have been implemented but generation curtailment is not, as its main purpose is to allow the connection of DG capacity beyond firm energy limits which tends to raise energy losses [26]. This planning orientated analysis assumes the measurement and control infrastructures to support the control schemes are in place, and that response delays are negligible.

\section{1) Coordinated Voltage Control}

Dynamic control of the substation transformer tap changer (OLTC) may allow more DG capacity to be connected by selecting the OLTC secondary voltage to allow maximum export from DG whilst ensuring upper and lower voltages are respected [26]. In each period the OLTC secondary voltage, $V_{\text {bоLTC,m }}$, is treated as a variable (not fixed) parameter, varying within the statutory range $\left(V_{b}^{(+,-)}\right)$:

$$
V_{b}^{-} \leq V_{b_{\text {OLTC }}, m} \leq V_{b}^{+}
$$

The OLTC model follows standard OPF practice in allowing the 'best' tap setting to be chosen. This differs from the strict voltage constraints applied in power flow and in the OLTC OPF models used in [30]-[33]. In effect OPF's choice is mimicking the decision process of the coordination system in selecting the voltage that delivers most benefit. 


\section{2) Adaptive Power Factor Control}

Many DG technologies can operate at a range of power factors. It is envisaged that DG can provide a scheme in which the power angle of each generator, $\phi_{g, m}$, is dispatched for each period within a given range $\left(\phi_{g}^{(+,-)}\right)$:

$$
\phi_{g}^{-} \leq \phi_{g, m} \leq \phi_{g}^{+}
$$

\section{Implementation}

The method was coded in the AIMMS optimisation modelling environment [38] and solved using the CONOPT 3.14A NLP solver. Simulations carried out on a PC (Intel Core2 2.13GHz, 2GB RAM) were delivered in around 3 seconds for firm generation cases (subsection IV.B) and 3 to 5 minutes for variable generation cases (subsections IV.C and D),depending on the analysis.

\section{CASE STUDY}

A generic UK medium voltage distribution network is used to demonstrate the multi-period AC OPF technique. The characteristics of the network and the corresponding demand and (renewable) generation data are presented first. In order to evaluate the impact not only of the optimal accommodation of variable generation, the loss minimisation problem also considers the Smart Grid control schemes presented earlier. In the sequence, the trade-off between energy losses and more renewable energy is investigated. Finally, the computational performance is briefly discussed.

\section{A. Network}

Fig. 4 shows the EHV1 Network, a 61-bus 33/11kV radial distribution system available in [39]. The feeders are supplied by two identical 30MVA $132 / 33 \mathrm{kV}$ transformers. The GSP voltage is assumed to be nominal while in the demand-only case (no DG), the OLTC at the substation has a target voltage of $1.045 \mathrm{pu}$ at the secondary. A voltage regulator (VR) is located between buses 304 and 321, with the latter having a target voltage of $1.03 \mathrm{pu}$. The OLTCs on the $33 / 11 \mathrm{kV}$ distribution transformers have a target voltage of 1.03pu (to ensure supply on the rural $11 \mathrm{kV}$ feeders within voltage limits). Voltage limits are $\pm 6 \%$ of nominal, reflecting UK practice. The total peak demand is 38MW.

Six wind generation sites are available considering two different wind profiles: WP1 and WP2. The group of buses 1105, 1106 and 1108 are considered to be sufficiently close geographically to all use the WP1 profile. The second profile is used by the remaining sites $(1113,1114,1115)$ located in the island connected by the subsea cable (line 318-304). While in the same geographic area, these two groups are far enough apart to have different, if related, wind profiles.

Demand and generation data correspond to central Scotland in 2003. The wind production data was derived from the UK Meteorological Office measured wind speed data and have been processed and applied to a generic wind power curve [37]. The discretisation and aggregation process presented in section III.A is applied to the 2003 hourly data. The extra wind profile means each scenario has an extra generation element, i.e., demand-generation-generation (e.g., 1.0pu$0.3 \mathrm{pu}-0.5 \mathrm{pu}$ ). The 8760 hours are reduced to an equivalent 56 periods. The aggregation process resulted in a load factor of 0.639 , and capacity factors of 0.415 and 0.483 , for WP1 and WP2, respectively. The error relative to the actual data is less than $1 \%$ in all cases, indicating that the method preserves the original behaviour. Table III (Appendix) presents the number of aggregated hours for each of the considered multi-periods (i.e., demand/generation/generation scenarios). The extra wind profile requires the inclusion of a set of new generators with associated variables and parameters within the appropriate constraints.

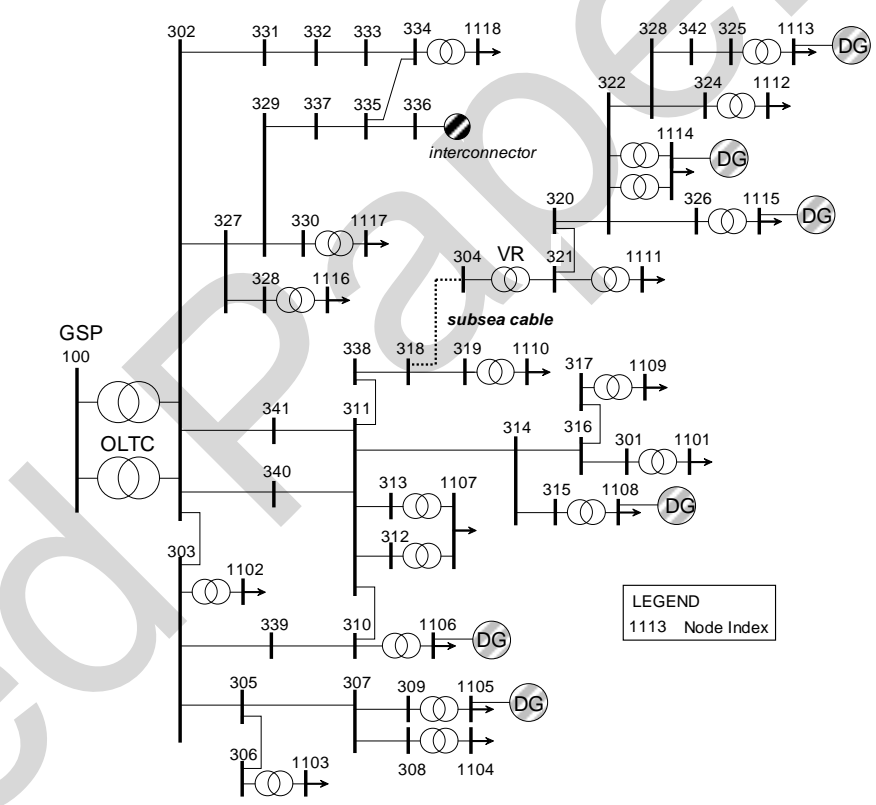

Fig. 4. UK GDS EHV1 Network [39] and potential locations for distributed wind power generation.

\section{B. Firm Generation}

Considering the original configuration without DG, at peak demand (38MW) power losses are $6.94 \%$ while in annual energy terms the aggregated demand profile from Table I implies an annual consumption of 214GWh and energy losses of $4.7 \%$ (comparable with typical UK rural networks).

First, the impact of firm (constant) generation on losses is studied for both the peak and variable demand scenarios. The network is operated as business as usual (BAU) without Smart Grid control schemes. The total DG capacity (at three different fixed power factor settings) and the corresponding losses found by the analysis are presented in Fig. 5. The energy analysis, able to evaluate the losses at every demand scenario, produces very different results from the peak analysis. Indeed, for this network, the annual energy losses can be reduced with a much smaller capacity than that found when only peak load is considered. Nonetheless, in both cases the technique is able to accommodate DG units such that losses are significantly reduced. For instance, unity power factor operation of generators (with 14.6MW total capacity) can decrease annual energy losses by $60 \%$. For peak demand only, the reduction is more than $70 \%$ but requires more than 22MW total capacity.

The corresponding breakdown of capacities for each DG 
unit (operating at unity power factor) is presented in Fig. 6. This particular figure indicates the most beneficial (loss wise) sizes of generators at each site. It can also be seen how the peak demand analysis results in larger capacity values as it inherently assumes that what is best at peak times is also the best at lower demand levels. In fact, overall annual energy losses can be minimised using a much lower installed capacity. The larger capacities suggested by the peak scenario will tend to promote higher overall energy losses (as a result of reverse power flows), and would exceed thermal and voltage limits during lower demand conditions. In this network more generation capacity is accommodated on the mainland given the proximity to the load centres. The most recurrent binding constraint (variable demand) corresponds to the thermal limit of the distribution transformer connecting DG unit 1108, but only during minimum demand conditions.

Focusing on the more complex variable demand scenario, Fig. 7 presents the percentage of energy losses with BAU operation of the network and the Smart Grid schemes coordinated voltage control (CVC) and adaptive power factor control $(\mathrm{PFc})$. It can be seen that the active management of the network improves its performance in terms of energy losses. Compared to BAU, the use of CVC and PFc, allows a further reduction of losses by adequately integrating more DG capacity (see Fig. 8). Indeed, with both Smart Grid-like control schemes in place, energy losses decreased by $77 \%$ from the original (no DG) configuration. However, this figure also shows that if the generators are operated at certain fixed power factors, and, in general, the network is managed as BAU, then an adequate power factor setting could provide similar loss reduction benefits as the sophisticated control mechanisms. A solution that, technically, could easily be implemented in most distribution networks, but that will probably face commercial and regulatory barriers.

\section{Variable Generation}

The major advantage of the proposed multi-period technique is its ability to cater not only for different states of demand but also the variability of renewable generation (subsection III.A). Differently from assessing the energy loss minimisation problem with constant generation, the multiperiod OPF is capable of considering in the optimisation the benefits or otherwise that result from a variable output.

Fig. 9 presents the minimum percentage energy losses that can be achieved if wind power generation is optimally accommodated under each operating strategy and without exceeding voltage or thermal limits. At first glance, it is clear that the losses will be greater than those when constant generation is adopted (Fig. 7). This is due to the variability of wind power generation and the limited reliance on power

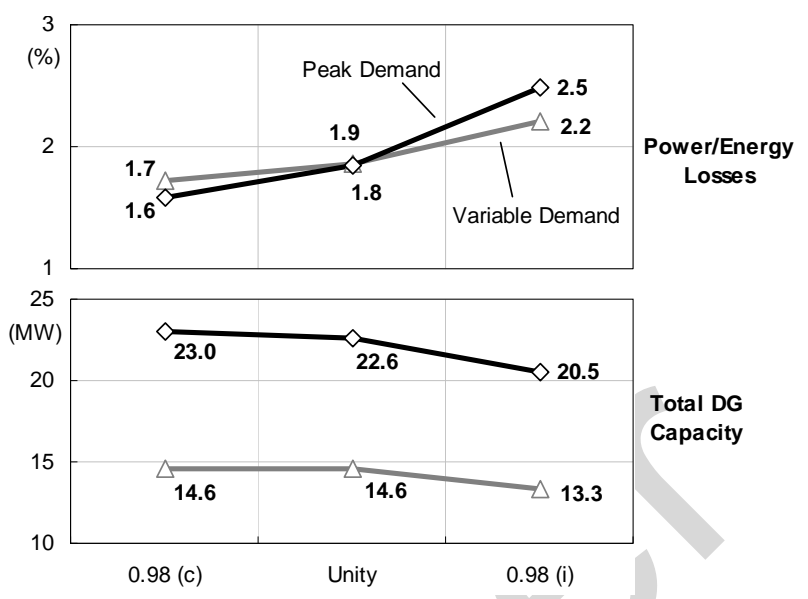

Fig. 5. (Top) Percentage losses and (bottom) total firm DG capacity that minimises losses in terms of power (peak demand scenario) and energy (variable demand scenario) at different fixed power factors (c: capacitive, and i: inductive).

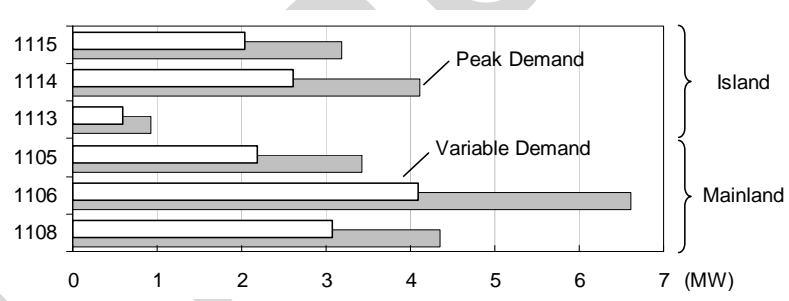

Fig. 6. Locational breakdown of firm DG capacities that minimise power and energy losses considering operation at unity power factor (case from Fig. 5).

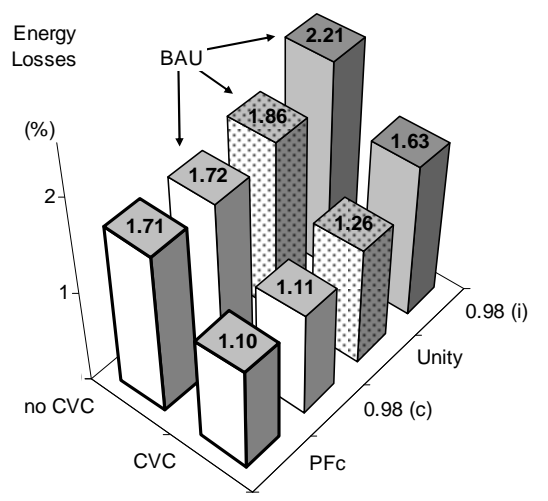

Fig. 7. Percentage of energy losses considering firm generation - business as usual operation and two different Smart Grid strategies (CVC: coordinated voltage control, PFc: adaptive power factor control).

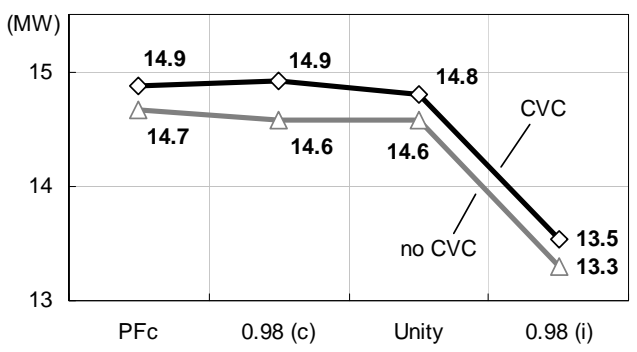

Fig. 8. Total DG capacity - business as usual operation and two different Smart Grid strategies.

provision at moments where it could be beneficial particularly at peak demand. However, compared to the original losses of 4.7\% significant gains are achieved when optimally accommodated. Assuming BAU management of the network 
unity power factor operation of the DG units sees energy losses reduced by $40 \%$. If coordinated voltage control is incorporated, then losses are cut by more than a half. From all the studied cases, the adoption of both CVC and adaptive power factor control lead to the lowest losses. Nonetheless, it is clear that, for this particular network, the largest benefits are brought about by the CVC scheme, raising the question of the cost effectiveness of using further control mechanisms.

In terms of installed capacity, Fig. 10 shows the total values found for each of the analysed cases. Due to the variable wind availability for the different demand levels, critical scenarios such as minimum and peak demand do not present maximum wind potential (see Table III). For this reason, more capacity than when considering constant generation can be connected to the network. It can also be seen that, again, generation capacity is strongly related to the reduction of losses. It is worth pointing out that while in most cases the CVC scheme only allows a marginal increase in capacity, when DG units are operated at 0.98 capacitive power factor, the gain is much more significant. This is primarily due to the ability of the CVC scheme to alleviate voltage rise problems. As for the PFc scheme, whilst it does provide lower losses, it is also clear that, for this network, similar gains can easily be achieved by setting the operation of the generators to unity or capacitive power factor.

A comparison of the individual capacities considering constant and variable generation is presented in Fig. 11, using both CVC and PFc schemes. As discussed previously, larger nominal capacities (with voltage and thermal limits taken account of) can be connected when wind power is analysed. However, although higher resources are available on the island area, due to the objective of reducing losses, more capacity is allocated closer to the load centres.

\section{Trade-Off Between Energy Losses and Renewable Energy}

Although energy losses will remain as an imperative for DNOs to drive network performance-related investments, it is also true that more renewable generation is needed to achieve environmental targets. This creates a tension where, on one hand, modest DG capacities promote energy efficiency while, on the other hand, greater DG capacities deliver higher renewable production and network asset use. This can be evaluated by adapting the objective function (1) to determine the generation capacity that maximises the net energy from renewable sources, i.e., the harvested wind energy minus the energy losses:

$$
\max \sum_{g \in G}\left(\sum_{m \in M} p_{g} \cdot \omega_{m} \cdot \tau_{m}\right)-\sum_{m \in M}\left(\sum_{l \in L} f_{l, m}^{1, P}+f_{l, m}^{2, P}\right) \cdot \tau_{m}
$$

where $p_{g}$ is the active capacity of generator $g(g \in G$, G is the set of generators). In period $m, \omega_{m}$ is the generation level relative to the nominal capacity as dictated by the variable (renewable) resource in that period.

The resulting trade-offs in terms of energy losses and wind power capacities are presented in Fig. 12. Given that the

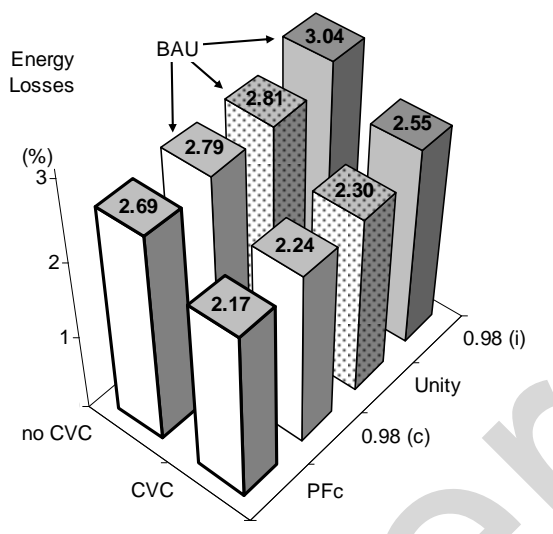

Fig. 9. Percentage of energy losses considering wind power generation business as usual operation and two different Smart Grid strategies.

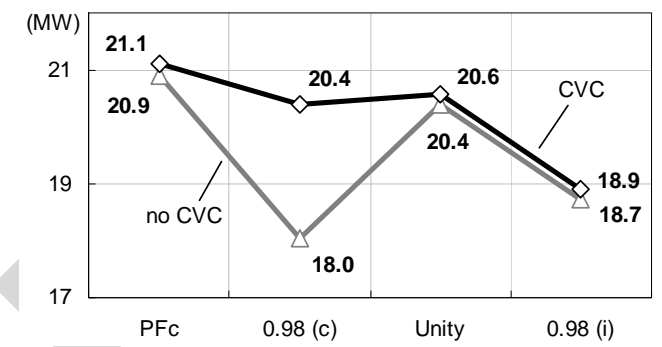

Fig. 10. Total DG capacity - business as usual operation and two different Smart Grid strategies.

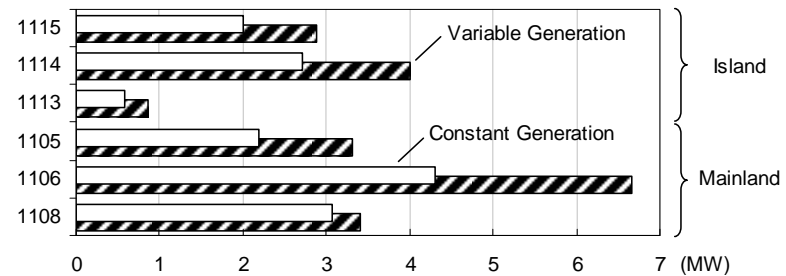

Fig. 11. Locational breakdown of variable and constant DG capacities that minimise energy losses considering both Smart Grid-like control schemes.
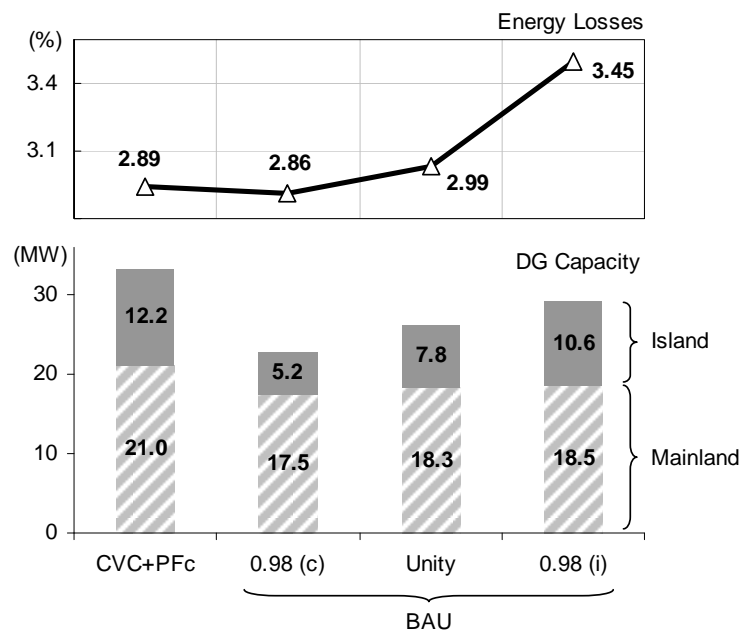

Fig. 12. (Top) Percentage of energy losses and (bottom) total DG capacity business as usual operation and two different Smart Grid strategies.

technique exploited the maximum net energy from renewable DG units, higher levels of capacity were accommodated, leading also to higher energy losses compared to those in the previous subsection (Fig. 9). In all the cases, thermal and voltage limits became binding for several lines (mostly those connecting the DG units) and nodes (those located at main 
interconnection points, e.g., 304).

With the net energy approach, it is possible to connect more than 26MW of wind power operating at unity power factor (no CVC) and reduce losses by $36 \%$. In terms of wind energy (and capacity), this represents an increase of $28 \%$ from the results found by the energy loss minimisation approach. When the new control mechanisms, CVC and PFc, are put in place, the total connectable wind power capacity exceeds 33MW and still leads to a significant reduction in losses. In other words, using Smart Grid-like control schemes, this network is capable of having a wind power capacity penetration of $87 \%$ (relative to the peak demand), that at the same time ensures loss levels lower than its original configuration.

The net energy approach is one way of comparing the relative merits of renewable energy production and network efficiency. A fuller picture of the trade-off could be gained from application of existing multi-objective analyses [21-24], that use weighting factors or the Pareto principle; the approach outlined in [40] could be readily adapted to this application.

It is important to recognize that such trade-offs must be seen in a system-level context with large penetrations of renewables displacing fossil fuelled generation albeit potentially with less than minimum network losses. One aspect of this revolves around the issue of whether 'all losses are equal' in that the costs and impacts (e.g., carbon intensity and primary energy) associated with electricity losses fed by renewable means are very different from those fed by fossil generators. This is clearly a much more substantial issue and an area for further work. The implications of this trade-off could be handled by the regulatory system through use of charging and reward schemes that properly reflect the impacts. In particular, there is an evident need to look at the regulation of Smart Grid investments that have been shown here to contribute to lower losses and higher renewable penetrations.

\section{CONCLUSIONS}

The minimisation of energy losses is and will be an important focus for DNOs in liberalised electricity markets. The growing interest in (renewable) generation connected at distribution levels represents an opportunity that, if harnessed correctly (through optimal accommodation or through incentives/economic signals), could help reduce energy losses. As demonstrated in this paper the practice of minimising power losses by examining only a single (peak) load condition is unlikely to lead to an overall optimal energy reduction. In addition the sole objective of minimising energy losses tends to compromise the potential renewable generation capacity that could be connected to distribution networks. Instead, a trade-off must be found where, in a regulatory framework in which excessive losses are penalised, the net benefit between low-carbon energy and losses is maximised.

The multi-period AC OPF-based technique has demonstrated that optimal accommodation combined with adequate power factor settings for the DG units can harvest significant benefits in terms of loss reduction. This less technically complex solution could easily be implemented in most distribution networks provided that potential commercial and regulatory barriers are alleviated through the use of incentives. Further gains can be achieved by the use of Smart Grid-like control schemes (coordinated voltage control and adaptive power factor control), although the economics of energy losses alone might not justify the required infrastructure.

\section{APPENDIX: SYSTEM AND ANALYTICAL DATA}

TABLE I. ANNUAL LOAD DURATION

\begin{tabular}{c|c|c|c|c|c}
\hline Demand (p.u.) & 1.0 & 0.9 & 0.7 & 0.5 & 0.3 \\
\hline Duration (hours) & 1 & 799 & 4615 & 3235 & 110 \\
\hline
\end{tabular}

TABLE II. LiNE AND TRANSFORMER PARAMETERS (RESISTANCE, REACTANCE, POWER FLOW LIMIT ON 100MVA BASE) OF THE SIMPLE TEST FEEDER

\begin{tabular}{c|c|c|c}
\hline Line & $\mathbf{R}$ & $\mathbf{X}$ & Smax \\
\hline $1-2{ }^{*}$ & - & 0.1250 & 0.6000 \\
\hline $2-3$ & 0.1960 & 0.1427 & 0.1550 \\
\hline $3-4$ & 0.1960 & 0.1427 & 0.1550 \\
\hline \multirow{4}{*}{ Considers the two parallel transformers }
\end{tabular}

TABLE III. MUlti-PERIODS - DEMAND AND GENERATION SCENARIOS

\begin{tabular}{|c|c|c|c|c|c|c|c|c|c|}
\hline Period & \begin{tabular}{|c|}
$\begin{array}{c}\text { Demand } \\
(\mathrm{pu})\end{array}$ \\
\end{tabular} & $\begin{array}{l}\text { WP1 } \\
\text { (pu) }\end{array}$ & $\begin{array}{l}\text { WP2 } \\
\text { (pu) }\end{array}$ & Hours & Period & \begin{tabular}{|c|}
$\begin{array}{c}\text { Demand } \\
(\mathrm{pu})\end{array}$ \\
\end{tabular} & $\begin{array}{l}\text { WP1 } \\
\text { (pu) }\end{array}$ & $\begin{array}{l}\text { WP2 } \\
(\mathrm{pu})\end{array}$ & Hours \\
\hline 1 & 0.3 & 0.0 & 0.0 & 1 & 29 & 0.7 & 0.1 & 0.3 & 362 \\
\hline 2 & 0.3 & 0.0 & 0.1 & 9 & 30 & 0.7 & 0.3 & 0.3 & 310 \\
\hline 3 & 0.3 & 0.1 & 0.1 & 50 & 31 & 0.7 & 0.3 & 0.5 & 429 \\
\hline 4 & 0.3 & 0.1 & 0.3 & 13 & 32 & 0.7 & 0.5 & 0.5 & 168 \\
\hline 5 & 0.3 & 0.3 & 0.3 & 7 & 33 & 0.7 & 0.5 & 0.7 & 334 \\
\hline 6 & 0.3 & 0.3 & 0.5 & 20 & 34 & 0.7 & 0.7 & 0.7 & 127 \\
\hline 7 & 0.3 & 0.5 & 0.5 & 5 & 35 & 0.7 & 0.7 & 0.9 & 377 \\
\hline 8 & 0.3 & 0.5 & 0.7 & 2 & 36 & 0.7 & 0.9 & 0.0 & 14 \\
\hline 9 & 0.3 & 0.7 & 0.7 & 1 & 37 & 0.7 & 0.9 & 0.9 & 668 \\
\hline 10 & 0.3 & 0.9 & 0.9 & 2 & 38 & 0.7 & 0.9 & 1.0 & 274 \\
\hline 11 & 0.5 & 0.0 & 0.0 & 148 & 39 & 0.7 & 1.0 & 0.9 & 185 \\
\hline 12 & 0.5 & 0.0 & 0.1 & 113 & 40 & 0.7 & 1.0 & 1.0 & 45 \\
\hline 13 & 0.5 & 0.1 & 0.1 & 875 & 41 & 0.9 & 0.0 & 0.0 & 41 \\
\hline 14 & 0.5 & 0.1 & 0.3 & 241 & 42 & 0.9 & 0.0 & 0.1 & 14 \\
\hline 15 & 0.5 & 0.3 & 0.3 & 255 & 43 & 0.9 & 0.1 & 0.1 & 195 \\
\hline 16 & 0.5 & 0.3 & 0.5 & 342 & 44 & 0.9 & 0.1 & 0.3 & 60 \\
\hline 17 & 0.5 & 0.5 & 0.5 & 118 & 45 & 0.9 & 0.3 & 0.3 & 35 \\
\hline 18 & 0.5 & 0.5 & 0.7 & 282 & 46 & 0.9 & 0.3 & 0.5 & 60 \\
\hline 19 & 0.5 & 0.7 & 0.7 & 81 & 47 & 0.9 & 0.5 & 0.5 & 23 \\
\hline 20 & 0.5 & 0.7 & 0.9 & 262 & 48 & 0.9 & 0.5 & 0.7 & 62 \\
\hline 21 & 0.5 & 0.9 & 0.0 & 8 & 49 & 0.9 & 0.7 & 0.7 & 11 \\
\hline 22 & 0.5 & 0.9 & 0.9 & 329 & 50 & 0.9 & 0.7 & 0.9 & 76 \\
\hline 23 & 0.5 & 0.9 & 1.0 & 118 & 51 & 0.9 & 0.9 & 0.0 & 11 \\
\hline 24 & 0.5 & 1.0 & 0.9 & 51 & 52 & 0.9 & 0.9 & 0.9 & 123 \\
\hline 25 & 0.5 & 1.0 & 1.0 & 12 & 53 & 0.9 & 0.9 & 1.0 & 40 \\
\hline 26 & 0.7 & 0.0 & 0.0 & 192 & 54 & 0.9 & 1.0 & 0.9 & 43 \\
\hline 27 & 0.7 & 0.0 & 0.1 & 127 & 55 & 0.9 & 1.0 & 1.0 & 5 \\
\hline 28 & 0.7 & 0.1 & 0.1 & 1003 & 56 & 1.0 & 0.3 & 0.5 & 1 \\
\hline
\end{tabular}

\section{REFERENCES}

[1] S. Civanlar, J. J. Grainger, H. Yin, and S. S. H. Lee, "Distribution feeder reconfiguration for loss reduction," IEEE Trans. on Power Delivery, vol. 3, no. 3, pp. 1217-1223, July 1988.

[2] D. Shirmohammadi and H. W. Hong, "Reconfiguration of electric distribution networks for resistive line losses reduction," IEEE Trans. on Power Delivery, vol. 4, no. 2, pp. 1492-1498, Apr. 1989.

[3] M. E. Baran and F. F. Wu, "Optimal sizing of capacitors placed on a radial distribution system," IEEE Trans. on Power Delivery, vol. 4, no. 1, pp. 735-743, Jan. 1989.

[4] M. E. Baran and F. F. Wu, "Optimal capacitor placement on radial distribution systems," IEEE Trans. on Power Delivery, vol. 4, no. 1, pp. 725-734, Jan. 1989.

[5] L. F. Ochoa, A. Padilha-Feltrin, and G. P. Harrison, "Evaluating distributed generation impacts with a multiobjective index," IEEE Trans. on Power Delivery, vol. 21, no. 3, pp. 1452-1458, July 2006.

[6] P. Chiradeja and R. Ramakumar, "An approach to quantify the technical benefits of distributed generation," IEEE Trans. on Energy Conversion, 
vol. 19, no. 4, pp. 764-773, Dec. 2004.

[7] C. L. T. Borges and D. M. Falcao, "Impact of distributed generation allocation and sizing on reliability, losses and voltage profile," in Proc. 2003 IEEE Power Tech, vol. 2, pp. 5.

[8] C. L. T. Borges and D. M. Falcao, "Optimal distributed generation allocation for reliability, losses, and voltage improvement," International Journal of Electrical Power \& Energy Systems, vol. 28, no. 6, pp. 413-420, July 2006.

[9] C. Wang and M. Hashem Nehrir, "Analytical approaches for optimal placement of distributed generation sources in power systems," IEEE Trans. on Power Systems, vol. 19, no. 4, pp. 2068-2076, Nov. 2004.

[10] P. M. Costa and M. A. Matos, "Avoided losses on LV networks as a result of microgeneration," Electric Power Systems Research, vol. 79, no. 4, pp. 629-634, Apr. 2009.

[11] N. Acharya, P. Mahat, and N. Mithulananthan, "An analytical approach for DG allocation in primary distribution network," International Journal of Electrical Power \& Energy Systems, vol. 28, no. 10, pp. 669678, Dec. 2006.

[12] T. Gozel and M. Hakan Hocaoglu, "An analytical method for the sizing and siting of distributed generators in radial systems," Electric Power Systems Research, vol. 79, no. 6, pp. 912-918, June 2009.

[13] N. S. Rau and Y.-H. Wan, "Optimum location of resources in distributed planning," IEEE Trans. on Power Systems, vol. 9, no. 4, pp. 2014-2020, Nov. 1994.

[14] W. El-Khattam, Y. G. Hegazy, and M. M. A. Salama, "An integrated distributed generation optimization model for distribution system planning," IEEE Trans. on Power Systems, vol. 20, no. 2, pp. 11581165, May 2005

[15] P. N. Vovos, A. E. Kiprakis, A. R. Wallace, and G. P. Harrison, "Centralized and distributed voltage control: Impact on distributed generation penetration," IEEE Trans. on Power Systems, vol. 22, no. 1, pp. 476-483, Feb. 2007.

[16] S.-H. Lee and J.-W. Park, "Selection of optimal location and size of multiple distributed generations by using Kalman filter algorithm," IEEE Trans. on Power Systems, vol. 24, no. 3, pp. 1393-1400, Aug. 2009.

[17] R. A. Jabr and B. C. Pal, "Ordinal optimisation approach for locating and sizing of distributed generation," IET Proceedings Generation, Transmission \& Distribution, vol. 3, no. 8, pp. 713-723, Aug. 2009.

[18] D. Singh, D. Singh, and K. S. Verma, "Multiobjective optimization for DG planning with load models," IEEE Trans. on Power Systems, vol. 24, no. 1, pp. 427-436, Feb. 2009.

[19] V. H. Mendez, J. Rivier, and T. Gomez, "Assessment of energy distribution losses for increasing penetration of distributed generation," IEEE Trans. on Power Systems, vol. 21, no. 2, pp. 533-540, May 2006.

[20] K. Nara, Y. Hayashi, B. Deng, K. Ikeda, and T. Achizawa, "Optimal allocation of dispersed generators for loss minimization," Electrical Engineering in Japan, vol. 136, no. 2, pp. 1-8, 2001.

[21] G. Celli, E. Ghiani, S. Mocci, and F. Pilo, "A multiobjective evolutionary algorithm for the sizing and siting of distributed generation," IEEE Trans. on Power Systems, vol. 20, no. 2, pp. 750-757, May 2005.

[22] L. F. Ochoa, A. Padilha-Feltrin, and G. P. Harrison, "Evaluating distributed time-varying generation through a multiobjective index," IEEE Trans. on Power Delivery, vol. 23, no. 2, pp. 1132-1138, Apr. 2008.

[23] L. F. Ochoa, A. Padilha-Feltrin, and G. P. Harrison, "Time-series based maximization of distributed wind power generation integration," IEEE Trans. on Energy Conversion, vol. 23, no. 3, pp. 968-974, Sep. 2008.

[24] A. Alarcon-Rodriguez, E. Haesen, G. W. Ault, J. Driesen, and R. Belmans, "Multi-objective planning framework for stochastic and controllable distributed energy resources," IET Renewable Power Generation, vol. 3, no. 2, pp. 227-238, Jun. 2009.

[25] Y. M. Atwa, E. F. El-Saadany, M. M. A. Salama, and R. Seethapathy, "Optimal renewable resources mix for distribution system energy loss minimization," IEEE Trans. on Power Systems, forthcoming issue.

[26] L. F. Ochoa, C. Dent, and G. P. Harrison, "Distribution network capacity assessment: Variable DG and active networks," IEEE Trans. on Power Systems, vol. 25, no. 1, pp. 87-95, Feb. 2010.

[27] L. F. Ochoa, C. J. Dent, and G. P. Harrison, "Maximisation of intermittent distributed generation in active networks," in Proc. 2008 CIRED Seminar: SmartGrids for Distribution, pp. 4.

[28] L. F. Ochoa, A. Keane, C. Dent, and G. P. Harrison, "Applying active network management schemes to an Irish distribution network for wind power maximisation," in Proc. 2009 International Conference on Electricity Distribution (CIRED), pp. 1-4.
[29] H. W. Dommel and W. F. Tinney, "Optimal power flow solutions," IEEE Trans. on Power Apparatus and Systems, vol. PAS-87, no. 10, pp. 1866-1876, Oct. 1968

[30] G. P. Harrison and A. R. Wallace, "Optimal power flow evaluation of distribution network capacity for the connection of distributed generation," IEE Proceedings Generation, Transmission \& Distribution, vol. 152, no. 1, pp. 115-122, Jan. 2005.

[31] P. N. Vovos and J. W. Bialek, "Direct incorporation of fault level constraints in optimal power flow as a tool for network capacity analysis," IEEE Trans. on Power Systems, vol. 20, no. 4, pp. 2125-2134, Nov. 2005.

[32] C. Dent, L. F. Ochoa, and G. P. Harrison, "Network distributed generation capacity analysis using OPF with voltage step constraints," IEEE Trans. on Power Systems, vol. 25, no. 1, pp. 296-304, Feb. 2010.

[33] C. Dent, L. F. Ochoa, G. P. Harrison, and J. W. Bialek, "Efficient secure AC OPF for network generation capacity assessment," IEEE Trans. on Power Systems, vol. 25, no. 1, pp. 575-583, Feb. 2010.

[34] P. N. Vovos and J. W. Bialek, "Optimal placement of reactive power compensation banks for the maximization of new generation capacity," International Journal of Emerging Electric Power Systems, vol. 4, no. 1 , pp. 1113, Nov. 2005.

[35] T. Boehme, A. R. Wallace, and G. P. Harrison, "Applying time series to power flow analysis in networks with high wind penetration," IEEE Trans. on Power Systems, vol. 22, no. 3, pp. 951-957, Aug. 2007.

[36] T. Boehme, G. P. Harrison, and A. R. Wallace, "Assessment of distribution network limits for non-firm connection of renewable generation," IET Proceedings Renewable Power Generation, vol. 4, no. 1, pp. 64-74, Jan. 2010.

[37] T. Boehme, J. Taylor, A. R. Wallace, and J. W. Bialek, "Matching renewable electricity generation with demand," Scottish Executive, Edinburgh, Feb. 2006.

[38] J. Bisschop and M. Roelofs, "AIMMS - The user's guide," Paragon Decision Technology, 2006

[39] Distributed Generation and Sustainable Electrical Energy Centre. United Kingdom Generic Distribution System (UK GDS). [Online]. Available: http://www.sedg.ac.uk/

[40] G. P. Harrison, A. Piccolo, P. Siano, and A. R. Wallace, "Exploring the trade-offs between incentives for distributed generation developers and DNOs," IEEE Trans. on Power Systems, vol. 22, no. 2, pp. 821-828, May 2007.

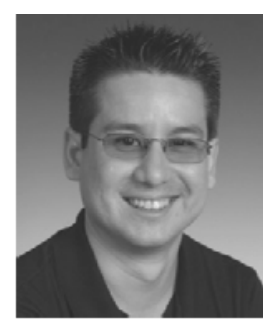

Luis F. Ochoa (S’01-M'07) is a Research Fellow at the Institute for Energy Systems, School of Engineering, University of Edinburgh, U.K. He obtained the Graduate degree from UNI, Lima, Peru, in 2000, and the M.Sc. and Ph.D. degrees from Sao Paulo State University (UNESP), Ilha Solteira, Brazil, in 2003 and 2006, respectively.

His current research interests include distribution system analysis and distributed generation. Dr. Ochoa is a member of IET.

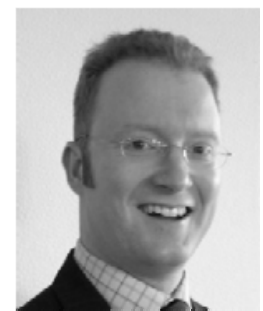

Gareth P. Harrison (M’02) is a Senior Lecturer in Energy Systems in the School of Engineering, University of Edinburgh, U.K.. His current research interests include network integration of distributed generation and analysis of the impact of climate change on the electricity industry.

Dr. Harrison is a Chartered Engineer and member of the Institution of Engineering and Technology, U.K. 